\title{
An evidence-based framework for predicting the impact of differing autotroph-heterotroph thermal sensitivities on consumer-prey dynamics
}

\author{
Zhou Yang ${ }^{1}$, Lu Zhang ${ }^{1}$, Xuexia Zhu ${ }^{1}$, Jun Wang ${ }^{1}$ and David JS Montagnes ${ }^{2}$ \\ ${ }^{1}$ Jiangsu Key Laboratory for Biodiversity and Biotechnology, School of Biological Sciences, Nanjing Normal \\ University, Nanjing, Jiangsu, China and ${ }^{2}$ Institute of Integrative Biology, University of Liverpool, Liverpool, UK
}

\begin{abstract}
Increased temperature accelerates vital rates, influencing microbial population and wider ecosystem dynamics, for example, the predicted increases in cyanobacterial blooms associated with global warming. However, heterotrophic and mixotrophic protists, which are dominant grazers of microalgae, may be more thermally sensitive than autotrophs, and thus prey could be suppressed as temperature rises. Theoretical and meta-analyses have begun to address this issue, but an appropriate framework linking experimental data with theory is lacking. Using ecophysiological data to develop a novel model structure, we provide the first validation of this thermal sensitivity hypothesis: increased temperature improves the consumer's ability to control the autotrophic prey. Specifically, the model accounts for temperature effects on auto- and mixotrophs and ingestion, growth and mortality rates, using an ecologically and economically important system (cyanobacteria grazed by a mixotrophic flagellate). Once established, we show the model to be a good predictor of temperature impacts on consumer-prey dynamics by comparing simulations with microcosm observations. Then, through simulations, we indicate our conclusions remain valid, even with large changes in bottom-up factors (prey growth and carrying capacity). In conclusion, we show that rising temperature could, counterintuitively, reduce the propensity for microalgal blooms to occur and, critically, provide a novel model framework for needed, continued assessment.

The ISME Journal (2016) 10, 1767-1778; doi:10.1038/ismej.2015.225; published online 18 December 2015
\end{abstract}

\section{Introduction}

Eukaryotic microbial rates (for example, growth, ingestion and photosynthesis) are expected to increase with anthropogenic and natural temperature rise, and critically these responses will also be altered by available resources (Montagnes et al., 2003; Allen et al., 2005; Kimmance et al., 2006; Bissinger, 2008; Montagnes et al., 2008; Knies and Kingsolver, 2010; Cross et al., 2015). Consequently, given the key role of these microbes (Kirchman, 2012), interactions between temperature and resource fluctuations will impact on ecosystem dynamics, often in unexpected ways. Here we address a globally important instance of this; the predicted increase in microalgal blooms with rising

Correspondence: Z Yang, School of Biological Sciences, Nanjing Normal University, 1 Wenyuan Road, Nanjing 210023, Jiangsu, China.

E-mail: yangzhou@njnu.edu.cn

or DJS Montagnes, Institute of Integrative Biology, University of Liverpool, BioSciences Building, Crown Street, Liverpool, L69 7ZB, UK.

E-mail dmontag@liv.ac.uk

Received 20 July 2015; revised 19 October 2015; accepted 6 November 2015; published online 18 December 2015 temperature (Kosten et al., 2012; Downing, 2014; Paerl, 2014) and the potential for eukaryotic microbes (protists) to prevent or suppress the development of such blooms.

Protists are major grazers of cyanobacteria and phytoplankton in aquatic systems (Caron et al., 2009), and clearly they too will be affected by temperature rise. In fact, there is a strong indication that the thermal sensitivity of heterotrophs is greater than that of autotrophs, and as temperature rises, microalgal blooms may be controlled by the faster population-response of these unicellular grazers (Allen et al., 2005; Rose and Caron, 2007; O'Connor et al., 2011; Aberle et al., 2012; Chen et al., 2012; Gilbert et al., 2014). Although, theoretical predictions have begun to explore the impacts of such disparate producer-consumer thermal responses (Rose and Caron, 2007; O'Connor et al., 2011), the argument has not been validated with empirical evidence. Likewise, temperature effects on protistalgal dynamics are complicated by two other, poorly addressed, issues. First, temperature has unique effects on functional and numerical responses (predator ingestion and growth rates vs prey abundance, respectively), which must be assessed independently to appreciate the impact of temperature 
on consumer-prey dynamics (Kimmance et al., 2006; Montagnes et al., 2008; Yang et al., 2013). Second, many, if not most, protistan consumers in fresh and marine waters are mixotrophic (they both photosynthesise and ingest prey; see Sanders, 2011; Flynn et al., 2013; Mitra et al., 2014), and within a mixotroph the relative role of autotrophy and heterotrophy can be temperature-sensitive (Heinze et al., 2013; Wilken et al., 2013). Therefore, temperature effects on the grazing and growth rates of mixotrophs also require careful evaluation.

We account for all of the above effects of temperature on consumer-prey dynamics by using empirically obtained data to develop and parameterise a novel approach to microbial population modelling. Specifically, we address the prediction that rising temperature will lead to increased top-down control, impeding the development of algal blooms. To do so, we adopted an experimental approach, using a highly relevant example: the toxic freshwater cyanobacterium Microcystis, which is ubiquitous and forms extensive blooms that disrupt aquatic ecosystems and poisons livestock, natural communities and humans (Paerl and Otten, 2013). In many freshwater systems micro-autotrophs are controlled by cladoceran grazing (Hessen and Kaartvedt, 2014), but microcystins, produced by Microcystis render it inedible/indigestible by many metazoa (Paerl and Otten, 2013; Ger et al., 2014). In contrast, hetero- and mixotrophic protists can ingest and grow on Microcystis (Nishibe et al., 2002; Kim et al., 2006; Wilken et al., 2010; Van Wichelen et al., 2012). Critically, protists, with growth rates similar to, or faster than, their prey may control algal blooms, even when metazoan grazers are present (Montagnes et al., 2008, and references within), and it has even been postulated that protists may control microcystin producing cyanobacteria. Here, we extend this prediction by suggesting that rather than temperature, unequivocally, increasing the prevalence of algal blooms (see Kosten et al., 2012; Downing, 2014; Paerl, 2014), protistan growth and grazing will disproportionately increase as temperature rises, and could via top-down control, aid in preventing the occurrence of blooms before they reach excessive levels.

More generally, by conducting this analysis, we provide a robust, novel modelling approach to consumer-prey dynamics that independently determines temperature dependence of prey logistic growth, the functional response and the numerical response, that is, we do not follow a classical Rosenzweig-MacArthur approach, where the prey and consumer population dynamics are coupled by assuming that consumer population growth is dependent on ingestion, a defined conversion efficiency and a defined mortality rate. Rather, we independently determine the numerical response, obviating the need to parameterise temperature effects on conversion efficiency and mortality rate (that is, the independent response (IR) model, see
Fenton et al., 2010). In this way, we are able to directly and independently explore the effect of temperature on consumer ingestion rate, growth rate and mortality, which is not generally appreciated in most, more traditional Rosenzweig-MacArthurbased consumer-prey models that explore temperature effects (for example, Fussmann et al., 2014).

We then validate the ability of the model to predict the consumer-prey dynamics, observed independently in microcosms. Finally, recognising that autotrophic growth rate $\left(r_{\mathrm{P}}\right)$ and carrying capacity $(K)$ are dependent on environmental factors beyond temperature (for example, light and nutrients), and these rates may interact with temperature (Chen et al., 2012), we explore how the model responds to altering these two parameters of the prey, within plausible limits. Ultimately, we indicate that even within the limits of a wide, realistic parameter space, the consumer is able to control the prey over a relatively short time period of days, and increased temperature reduces this time. Thus, using model organisms (Van Donk et al., 2009; Wilken et al., 2010, 2013, 2014) and the IR model structure, we provide strong inference that as temperature rises the relative impact of protists as top-down controllers of autotrophic prey will increase, potentially controlling, or preventing, algal blooms. In fact, this seems to be the first empirical validation of hypotheses associated with the impact of disparate thermal sensitivities of auto- and heterotrophic processes.

\section{Materials and methods}

Organisms and maintenance of cultures

The prey (a cyanobacterium, Microcystis aeruginosa, FACHB 927, Institute of Hydrobiology, Chinese Academy of Sciences) was maintained in axenic batch culture (BG-11 medium, Rippka et al., 1979) at $25^{\circ} \mathrm{C}$ and $40 \mu \mathrm{mol}$ photons $\mathrm{m}^{-2} \mathrm{~s}^{-1}$ (light:dark, 12:12 h). The consumer (a mixotrophic flagellate, Ochromonas sp., isolated from Lake Taihu, East China) was maintained under the conditions described and fed M. aeruginosa.

\section{Prey growth response to temperature}

Logistic growth parameters, specific growth rate $\left(r_{\mathrm{P}}\right)$ and carrying capacity $(K)$, were determined at 14,16 , $19,20,22,25,28$ and $31^{\circ} \mathrm{C}$. At each temperature, triplicate cultures were maintained in $250 \mathrm{ml}$ flasks, at $40 \mu \mathrm{mol}$ photons $\mathrm{m}^{-2} \mathrm{~s}^{-1}$ (light:dark, 12:12 h), as these are typical conditions for the upper water column of freshwater lakes where the consumer and prey occur. Cultures were acclimated to temperatures (5 days), and then change in population abundance was determined daily over 20-90 days, depending on the temperature. Samples were Lugol's fixed ( $2 \%$ ) and enumerated microscopically. The carrying capacity (when cultures remained at a 
maximum constant level for $>8$ days) and the initial exponential growth rate over the first 10-20 days (depending on the temperature) were determined. Regression analysis was applied to assess the relation between these two parameters and temperature.

\section{Consumer ingestion and growth response to prey and} temperature

Consumers were acclimated (5 days) to a range of prey levels (from near zero up to $\sim 2 \times 10^{6}$ cells ml $^{-1}$, with more measurements at low levels), at 13, 16, 19, $22,25,28$ and $31^{\circ} \mathrm{C}$, at $40 \mu \mathrm{mol}$ photons $\mathrm{m}^{-2} \mathrm{~s}^{-1}$. The consumer was added to $150-\mathrm{ml}$ flasks containing $100 \mathrm{ml}$ of prey, at an initial predator density of $\sim 1.0 \times 10^{4} \mathrm{ml}^{-1}$. Then, mixed cultures were acclimated for a further $24 \mathrm{~h}$ at each temperature, after which prey and consumer numbers were determined, as initial abundances. Then, during $48 \mathrm{~h}$, incubation cultures were mixed three times daily, and samples $(2 \mathrm{ml})$ were taken after 24 and $48 \mathrm{~h}$ and enumerated as above. Controls (without consumers) for prey growth, alone, were conducted under conditions identical to the consumer-prey treatments.

Ingestion rate ( $I$, prey consumer ${ }^{-1}$ day $\left.^{-1}\right)$ was determined from measurements of the depletion of prey in experimental containers, compared with change in prey in controls, following methods that account for changes in both consumer and prey abundance over time (esablished by Heinbokel (1978) and outlined in detail by Båmstedt et al. (2000)). Consumer-specific growth rate ( $r$, per day) was assumed to be exponential and determined as the slope of $\ln$ abundance vs time over $48 \mathrm{~h}$.

\section{Time-series data of consumer-prey dynamics}

The consumer and prey were introduced to $250 \mathrm{ml}$ flasks containing $150 \mathrm{ml}$ of media at two consumers: prey density regimes: $\sim 500: 10^{5} \mathrm{ml}^{-1}$ and $2 \times 10^{4}$ : $10^{6} \mathrm{ml}^{-1}$. Incubations were maintained at $14,16,19$, 22, 25, 28 and $31^{\circ} \mathrm{C}$ for the first regime and 15, 20, 25 and $28{ }^{\circ} \mathrm{C}$ for the second. All flasks were maintained at $40 \mu \mathrm{mol}$ photons $\mathrm{m}^{-2} \mathrm{~s}^{-1}$, with three replicates at each temperature. Over 13 days, flasks were regularly mixed, sampled daily $(2 \mathrm{ml})$ and enumerated as above. Data from these incubations (and others not shown) were also used to determine the relation between consumer maximum yield (consumer carrying capacity) and maximum prey abundance (see next section).

\section{Developing response equations}

For modelling purposes, we established functions that predict consumer ingestion rate and specific growth rate in response to temperature and prey concentrations. Our starting point was to follow standard practices for data, like ours, that exhibit a rectangular hyperbolic (Holling Type II) response of rates to prey abundance (Supplementary Figure S1); these were then modified to account for a mixotrophic consumer. First, ingestion rate (I, preyconsumer $^{-1}$ day $^{-1}$ ) was assumed to vary with prey concentration $\left(P, \mathrm{ml}^{-1}\right)$, following the, mechanistic, Holling Type II response (equation 1), where $I_{\max }$ is the asymptotic maximum ingestion rate, and $k$ is a constant describing the shape of the response $(k+t$ is equivalent to the half-saturation constant); a threshold prey level $\left(t, \mathrm{ml}^{-1}\right)$ was also included, below which ingestion ceased, presumably as autotrophy took precedence. Second, consumer-specific growth rate $\left(r, \mathrm{~d}^{-1}\right)$ was assumed to follow a similar rectangular hyperbolic response, with a negative x-intercept $\left(P^{\prime}, \mathrm{ml}^{-1}\right)$ associated with autotrophic growth rate, where $r_{\max }$ is the maximum asymptotic growth rate and $k_{1}$ describes the shape of the response (equation 2).

$$
\begin{aligned}
& I=\frac{I_{\max }(P-t)}{k+(P-t)} \\
& r=\frac{r_{\max }\left(P+P^{\prime}\right)}{k_{1}+\left(P+P^{\prime}\right)}
\end{aligned}
$$

Then, as indicated above, based on these mechanistic functions, phenomenological responses were determined, where $I_{\max }, k, r_{\max }$ and $k_{1}$ were influenced by temperature $\left(T,{ }^{\circ} \mathrm{C}\right)$ : consumer ingestion rate $\left(I_{\mathrm{t}}\right)$ was best predicted by equation 3 , and consumer growth rate $\left(r_{t}\right)$ was best predicted by equation 4, where $a$ to $f$ are constants used to fit responses, with no underlying mechanistic basis. Variants of equations 3 and 4 were examined that included a range of temperature-dependent elements (for example, power, exponential and polynomial functions); being the most parsimonious and yielding the best fit (with the highest adjusted $R^{2}$ ), equations 3 and 4 were adopted (functions yielding poorer fits are not presented here). This exploration produced responses that reveal trends and reflect ecophysiological phenomena, which were then used in the IR model. Note, also, that fits were obtained by relating consumer growth or ingestion responses to treatment temperatures and geometric mean prey concentration (Heinbokel, 1978), and equations 3 and 4 were fit to data using the Marquardt-Levenberg algorithm (SigmaPlot 11, Systat Software Inc., San Jose, CA, USA). Adjusted $R^{2}$ values for the responses and standard errors of the estimates were used to indicate goodness of fit.

$I_{T}=\frac{(a+b / T)(P-t)}{T C+(P-t)}$

$r_{T}=\frac{(d+e T)\left(P+P^{\prime}\right)}{f T+P+P^{\prime}}$

Finally, it became clear in the time-series incubations that final consumer abundance (consumer maximum yield), when prey were exhausted and the consumer maintained itself by autotrophy, was 
dependent on the maximum prey abundance during the incubation (see Results and Discussion). To incorporate this phenomenon into simulations, the final carrying capacity of the consumer (averaged over several days) was regressed against the maximum prey abundance during the incubation, to determine a relationship for predicting the carrying capacity (yield) of the predator (see Discussion). In total, 54 time-series incubations were examined, ranging from 0 to $\sim 2 \times 10^{6}$ prey $\mathrm{ml}^{-1}$ at the maximum (from data presented in Results and other shorter incubations not presented here).

\section{Modelling consumer-prey dynamics}

To assess the extent to which temperature impacts consumer control of prey, a model was constructed where prey grew following a logistic response, prey were removed strictly by the consumer and consumer ingestion, growth and mortality rates were prey-dependent. This is based on the IR model structure of Fenton et al. (2010), as outlined in the Introduction, and equations 5 and 6 describe the model,

$\frac{d P}{d t}=r_{\mathrm{P}}\left(1-\frac{P}{K}\right) P-I_{T} C$

$\frac{d C}{d t}=r_{T}\left(1-\frac{C}{f\left(P_{\mathrm{p}}\right)}\right) C$

where: $P=$ prey abundance; $r_{\mathrm{P}}=$ prey-specific growth rate, with temperature-dependent growth rate and a single temperature-independent carrying capacity $(K$, see Results, 'A linear change in maximum rates with increasing temperature'); $C=$ consumer abundance; $I_{T}$ and $r_{T}$ are temperature and prey-dependent consumer grazing (equation 3) and growth (equation 4) rates, respectively; and $f\left(P_{\mathrm{p}}\right)$ is the consumer carrying capacity, dictated by the peak abundance of the prey $\left(P_{\mathrm{p}}\right)$, achieved over the simulation (see Results, 'Time-series data of consumer-prey dynamics').

Using the above model, consumer-prey dynamics were simulated at a range of temperatures and initial organism abundances, matching empirical incubations (see Results, 'Observed consumer-prey dynamics'). The predictive ability of the model was assessed in two ways: (1) the predicted consumer and prey abundances were compared to observed data, that is, residuals were computed as (observedpredicted)/observed, and the deviation from zero was assessed; and (2) the predicted time to prey 'extinction' was compared with the observed time to prey becoming virtually extinct (note that as the consumer ceased grazing at $\sim 4 \times 10^{3}$ prey $\mathrm{ml}^{-1}$, complete extinction was not achieved).
Exploring sensitivity to prey-related bottom-up parameters

Recognising that autotrophic growth rate $\left(r_{\mathrm{P}}\right)$ and carrying capacity of the autotroph $(K)$ are dependent on environmental factors beyond temperature (for example, light and nutrients), we explore model predictions by altering these two parameters within plausible limits. Specifically, we assessed how two factors varied: (1) the time required for the predator to drive the prey towards extinction; and (2) the maximum number of prey at the peak of the bloom. The IR predator-prey model (equations 5 and 6) was parameterised as above ('Modelling consumer-prey dynamics'), but $r_{\mathrm{p}}$ was multiplied by values ranging from 0.2 to 3 , and $K$ was multiplied by values ranging from $10^{-3}$ to 10 ; these multipliers relate to plausible, natural levels for small autotrophs (that is, under eutrophic conditions, there could potentially be $4-5$ doublings in a day at $30^{\circ} \mathrm{C}$, and maximum abundances could be $\sim 10^{8} \mathrm{ml}^{-1}$; likewise, under highly oligotrophic conditions, minimum growth levels could be close to zero and maximum abundances could reach only $\sim 10^{4} \mathrm{ml}^{-1}$ (Reynolds, 1984). All simulations were initiated with $10^{5}$ prey $\mathrm{ml}^{-1}$ and $10^{3}$ consumers $\mathrm{ml}^{-1}$, similar to many of our microcosm incubations.

\section{Results}

\section{A linear change in maximum rates with increasing} temperature

Prey growth rate $\left(r_{\mathrm{P}}\right.$, day $\left.^{-1}\right)$ exhibited a significant $(P<0.01)$ linear increase with increasing temperature, between 14 and $30^{\circ} \mathrm{C}$, with a slope of $0.041 \pm 0.002$ (s.e.m.) and an intercept of $-0.447 \pm 0.03$ (Figure 1a); at $31^{\circ} \mathrm{C}$ growth rate dropped to 0.5 . Prey carrying capacity $\left(K, \mathrm{ml}^{-1}\right)$ was invariant with temperature (linear regression, $P=0.12$ ), with a mean of $1.46 \times 10^{7} \pm 1.02 \times 10^{5}$ (Figure $1 \mathrm{~b}$ ).

Consumer maximum growth $\left(r_{\max }\right.$, day $^{-1}$, obtained from Supplementary Figure S1) exhibited a significant $(P<0.01)$ linear increase with increasing temperature, between 13 and $28^{\circ} \mathrm{C}$, with a slope of $0.115 \pm 0.0065$ (s.e.m.) and an intercept of $-1.146 \pm 0.14$; at $31^{\circ} \mathrm{C}$ growth rate plateaued (Figure 1c). Maximum ingestion rate $\left(I_{\max }\right)$ exhibited a significant $(P<0.01)$ linear increase with increasing temperature, between 13 and $25^{\circ} \mathrm{C}$, with a slope of $1.16 \pm 0.107$ (s.e.m.) and an intercept of $-11.8 \pm 2.07$; at $25^{\circ} \mathrm{C}$ growth rate plateaued (Figure $1 \mathrm{~d}$ ).

\section{Interaction between temperature and prey abundance on rates}

When all data for growth rate or ingestion rate were assessed (Figure 2), they provided good predictive functions, with adjusted $R^{2}$ for ingestion (Figure 2a) and growth (Figure $2 \mathrm{~b}$ ) responses to temperature and prey abundance of 0.79 and 0.89 , respectively. The functions followed equations 3 and 4, with the parameter values ( \pm s.e.m.): $a=29.47 \pm 2.21$ (prey day ${ }^{-1}$ ); 

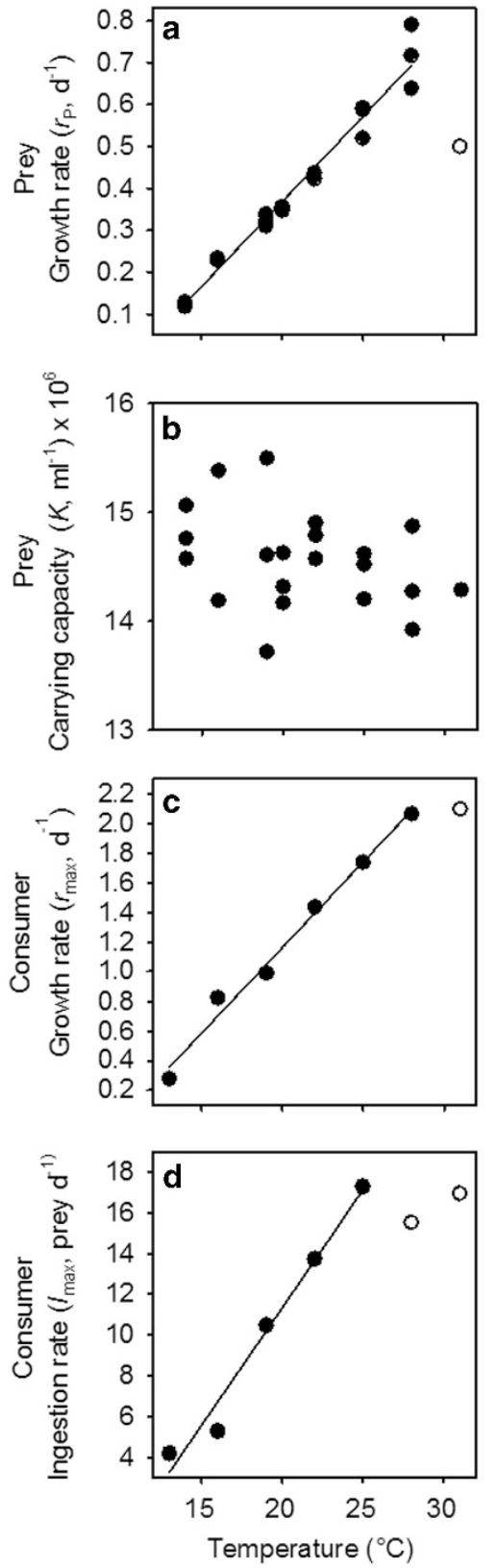

Figure 1 The response of the prey and consumer to temperature. (a) The linear relation between prey growth rate and temperature between 14 and $28^{\circ} \mathrm{C}$ (solid points) and the decrease at $31^{\circ} \mathrm{C}$ (open point); see Results for parameters of the linear regression. (b) The lack of effect of temperature on prey carrying capacity. (c) The relation between consumer maximum growth rate and temperature. (d) The relation between consumer maximum ingestion rate and temperature.

$b=-356.45 \pm 32.0 \quad$ (prey day $^{-1} \quad{ }^{\circ} \mathrm{C}$ ); $\quad c=7526.85 \pm$ 1644.87 (prey $\mathrm{ml}^{-1}{ }^{\circ} \mathrm{C}^{-1} ; \quad t=3615.63 \pm 7413.23$ (prey $\left.\mathrm{ml}^{-1}\right) ; d=-1.47 \pm 0.09 ;\left(\right.$ day $\left.^{-1}\right) ; e=0.12 \pm 0.01$ $\left(\right.$ day $\left.^{-1}{ }^{\circ} \mathrm{C}^{-1}\right) ; f=272.75 \pm 74.59\left(\right.$ prey $\mathrm{ml}^{-1}{ }^{\circ} \mathrm{C}^{-1}$ ); and $P^{\prime}=5912.47 \pm 1793.90\left(\right.$ prey $\left.\mathrm{ml}^{-1}\right)$.

Observed consumer-prey dynamics

The consumer drove the prey to, or towards, extinction in all incubations, except for one replicate
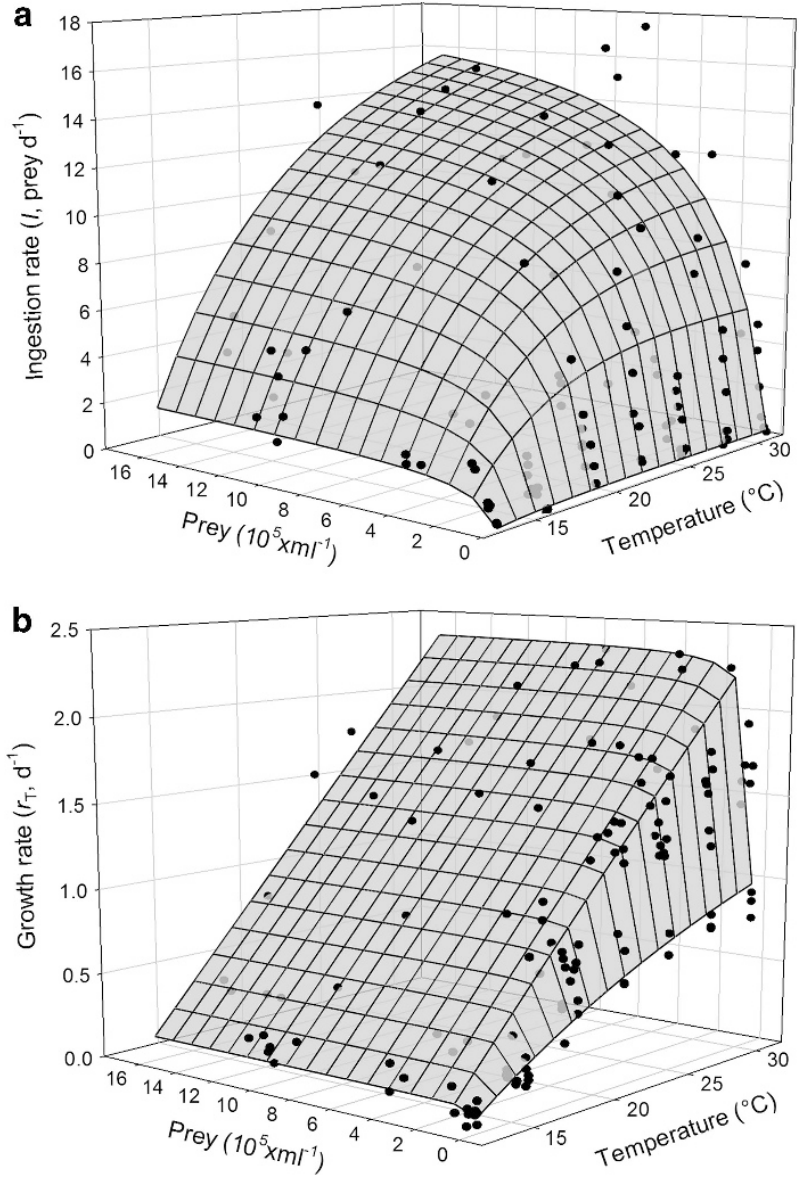

Figure 2 Responses of consumer ingestion (a) and growth (b) rates to prey abundance and temperature. Points are measurements and response planes are the fit of equation 3 (ingestion) and equation 4 (growth) to the data. See Results for parameters, error estimates and adjusted $R^{2}$ for the fits to the data. Note, black points are above the response plain, while grey points are below it.

at $14^{\circ} \mathrm{C}$ (Figure 3, Supplementary Figures S2). The time to extinction decreased from $\sim 9$ to 3 days with increasing temperature (Figure 4a). There was a strong relation between the final consumer carrying capacity $\left(K_{\mathrm{C}}\right)$ and the peak in prey $P_{\mathrm{P}}$ abundance $\left(\mathrm{ml}^{-1}\right)$, providing the predictive equation (Figure 5): $K_{\mathrm{C}}=P_{\mathrm{P}} 0.7058+12330\left(P<0.001, R^{2}=0.98\right)$.

Comparison of observed and simulated consumer-prey dynamics

Simulations, following the modified IR model structure (see Materials and Methods) provided good estimates of consumer-prey dynamics, except at $14{ }^{\circ} \mathrm{C}$ where they were very poor (Figures 3 and 6, Supplementary Figures S2 and S3); the residuals ((observed-predicted)/observed) for the prey were marginally, significantly greater than zero $(0.287$, $\alpha=0.05$, Wilcoxon one sample test, SPSS, V 21, IBM, Portsmouth, UK), while the residuals for the consumer did not significantly differ from zero (Figure 6). Likewise, simulations supported observations that as temperature increased the time for the 

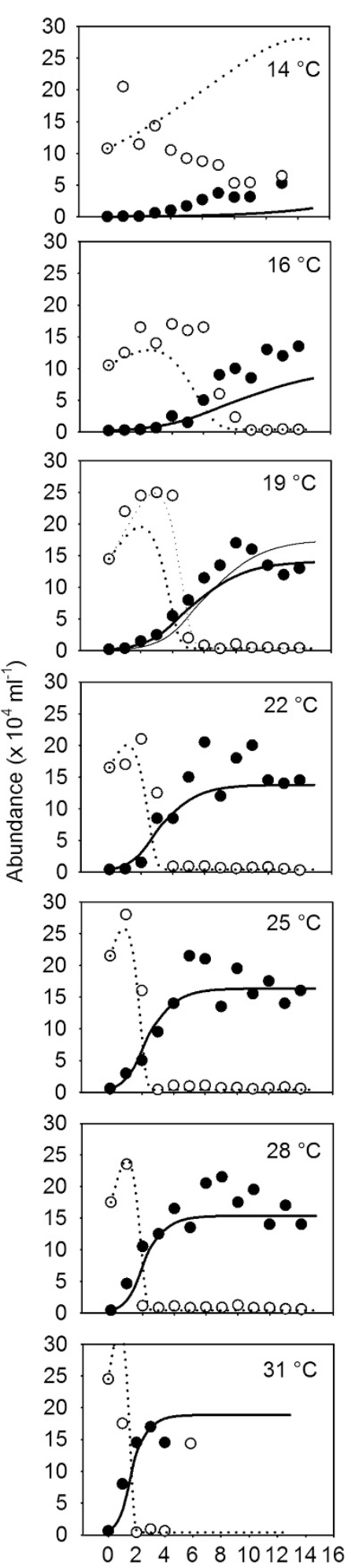

Figure 3 Time-series data for prey (open points and dotted line) and consumer (solid points and solid line) at temperatures ranging from 14 to $31^{\circ} \mathrm{C}$. Points are data collected in incubations; lines are model simulations (see Materials and Methods for details of the model). For the $19^{\circ} \mathrm{C}$ panel, the fine lines are simulated when initial consumer abundance was reduced by $50 \%$, to illustrate the sensitivity of initial level estimates (see text for details). Note, see Supplementary Figures S2 and S3 for other incubations and model simulations. a
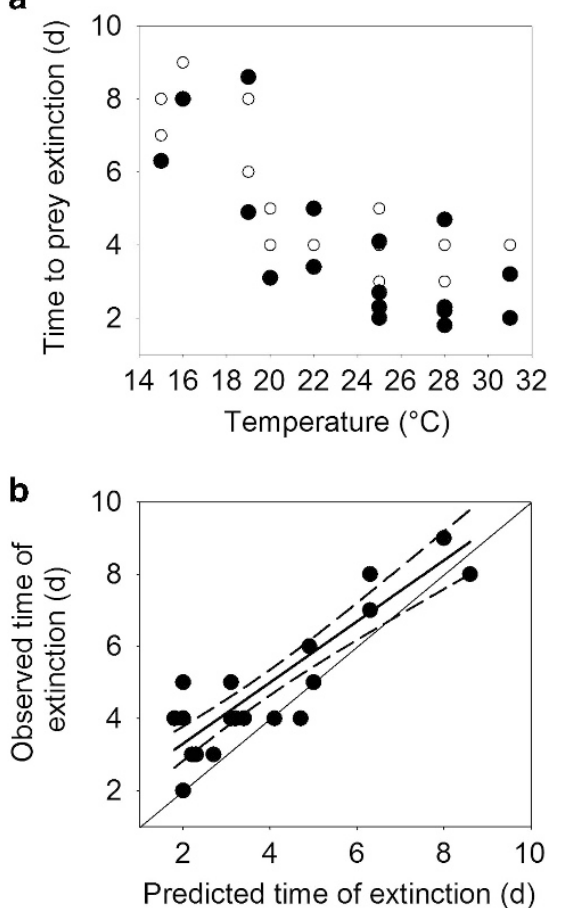

Figure 4 Estimates on the time required for the consumer to drive the prey to extinction. (a) The effect of temperature on the extinction time from empirical data (open circles) and model simulations (solid circles). (b) The relation between the extinction time predicted by the model and the observed (empirical) estimate; the solid thin line represents the 1:1 predictions; the solid thick line is the least squares regression though the data, with its $95 \%$ confidence interval (dashed lines).

consumer to drive prey towards extinction decreased (Figure 4a). There was a significant relation between observed and predicted times to virtual prey extinction $\left(P<0.001, R^{2}=0.89\right)$, with a slope not significantly differring from $1 \quad(\alpha=0.05)$, although on average, the model predicted the time to extinction to be $\sim 1$ day earlier than that observed ( $t$-test, $\alpha=0.05$ ) (Figure $4 b$ ).

\section{Exploring the impact of prey-related parameters}

Altering the temperature-dependent prey growth rate, by multiplying it by a factor of 0.2 to 3 , affected the time (4-16 days) for the predator to reduce the prey to $\sim 4 \times 10^{3}$ prey $\mathrm{ml}^{-1}$ (that is, the threshold feeding level of the consumer, $t$ ) and the peak abundance $\left(10^{5}-10^{7} \mathrm{ml}^{-1}\right)$ of the prey bloom (Figures $7 \mathrm{a}$ and c). Likewise, altering the temperature-dependent prey carrying capacity, by multiplying it by a factor of $10^{-3}-10$, affected the time (3-9 days) for the consumer to reduce the prey to $\sim 4 \times 10^{3}$ prey $\mathrm{ml}^{-1}$ and the peak abundance $\left(10^{5}-\right.$ $2.2 \times 10^{5} \mathrm{ml}^{-1}$ ) of the prey bloom (Figures $7 \mathrm{~b}$ and $\mathrm{d}$ ). In all cases the consumer was still capable of driving the prey close to extinction in fewer than 20 days, indicating the ability of the consumer to prevent prey blooms occurring. 


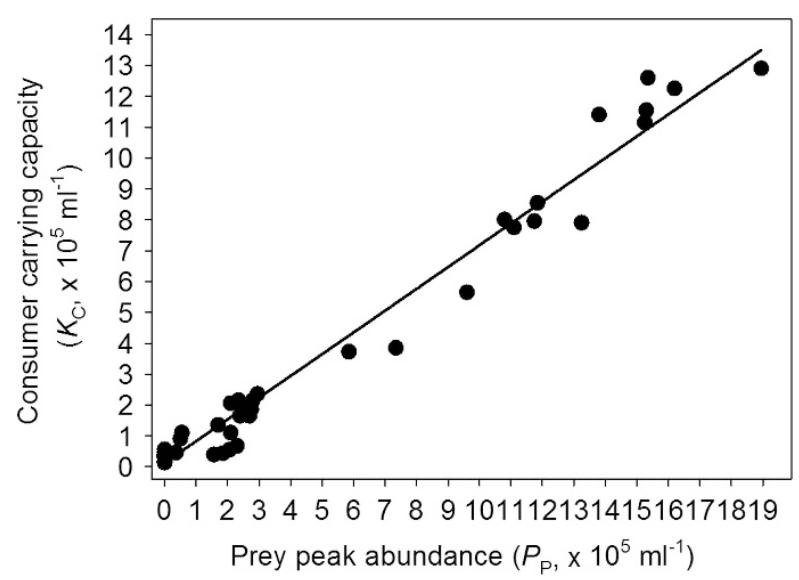

Figure 5 The relation between peak prey abundance $\left(P_{\mathrm{P}}\right)$ and the final constant abundance of consumers (the carrying capacity $K_{\mathrm{C}}$ ), after prey were exhausted. See the Materials and Methods for a description of the data. The line is the least squares regression though the data; see the Results for the parameters.

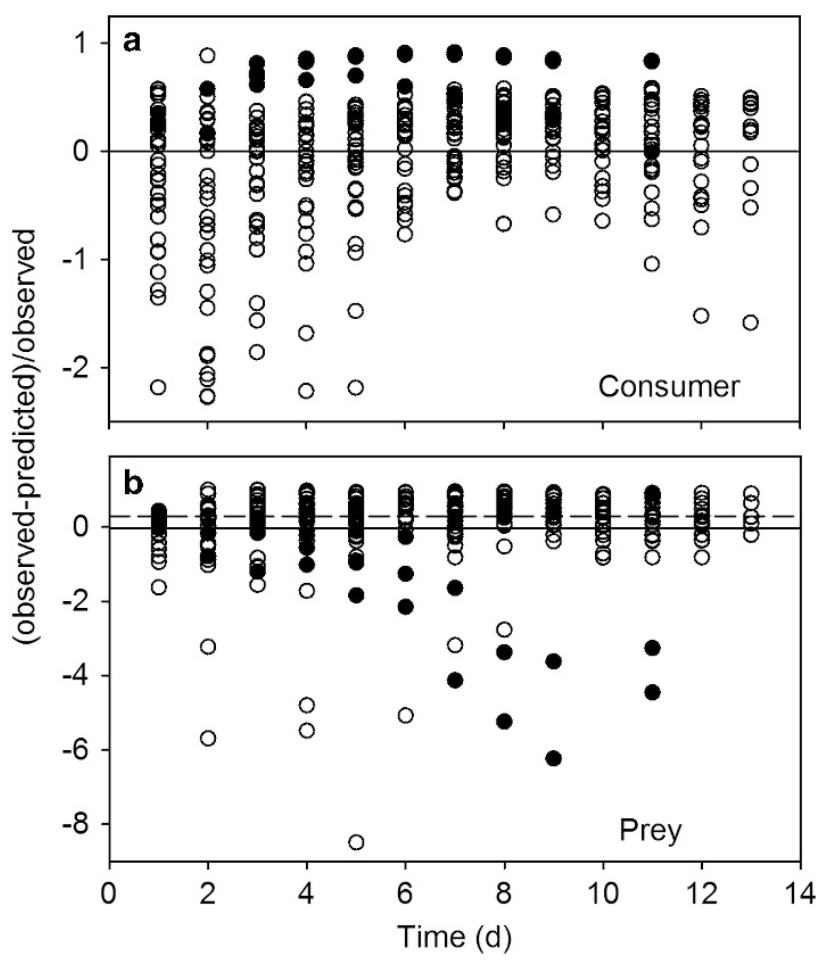

Figure 6 The residuals of a comparison between empirical incubations and model simulations (for example, Figure 3) for the consumer (a) and the prey (b). Solid dots are data from $14{ }^{\circ} \mathrm{C}$ incubations and are not included in the statistical analysis. The solid line indicates zero. The dashed line (b) is the median value of the residuals; the median values of the residuals for the consumer was not significantly different from zero.

\section{Discussion}

Over the past decade, meta-analyses and theoretical explorations have argued that photoautotrophs exhibit lower thermal responses than their consumers, potentially destabilising producer-consumer dynamics with increasing temperature (Allen et al., 2005; Rose and Caron, 2007; O'Connor et al., 2011; Chen et al., 2012; Gilbert et al., 2014). Few studies have explored these predictions, but those that do are supportive (Aberle et al., 2012). Here, using a model system that has the virtue of being a global component of freshwater food webs with substantial economic importance, we adopt a new approach to modelling that provides the first empirical test of the above prediction. In doing so we: (1) generate empirical evidence to validate arguments that consumers are more temperature-sensitive than their autotrophic prey; (2) challenge predictions that temperature rise will unequivocally lead to increased occurrence of toxic algal blooms (O'Neil et al., 2012; see Newcombe et al., 2012; Paerl and Otten, 2013), by indicating that increased temperature enhances top-down control; and (3) explore, and question, predictions that with increasing temperature, conditions that reduce producer growth rate and abundance (for example, reduced light or nutrients) may interact to lessen the impact of the consumer (Chen et al., 2012).

A new model framework

Reaching the above conclusions required a new approach to population modelling. By evaluating temperature-dependent growth and grazing responses (that is, our work and that of others: Figures 1 and 2, Supplementary Figure S1; Kimmance et al., 2006; Montagnes et al., 2008; Wilken et al., 2013; Yang et al., 2013), we have recognised the need to significantly modify the traditional modelling of consumer (and specifically mixotroph) and prey dynamics. Below we defend these changes and argue for their general adoption.

First, the metabolic theory of ecology contends that auto- and heterotrophic rates increase exponentially, with photosynthesis being less temperaturedependent than respiration (for example, Allen et al., 2005). We support the latter part of the above expectation: the autotrophic prey had a lower thermal sensitivity than its consumer (Figures 1a, c and d). However, supporting previous meta-analyses (Montagnes et al., 2003; Bissinger, 2008), we found that maximal rates of auto- and heterotrophic growth and heterotrophic grazing, when examined at the species level, were approximated by a linear increase with temperature (Figure 1), rather than applying an exponential response. This does not reject the wellfounded observations that, across taxa, metabolic rates increase exponentially with temperature and that many species-based metabolic rates also increase exponentially (for example, Allen et al., 2005). It does, however, suggest that the response of species-specific maximum growth and ingestion rates (both being the combination of several metabolic processes, with potentially different thermal sensitivities) may be better represented by a linear model. Recognising this distinction may improve 

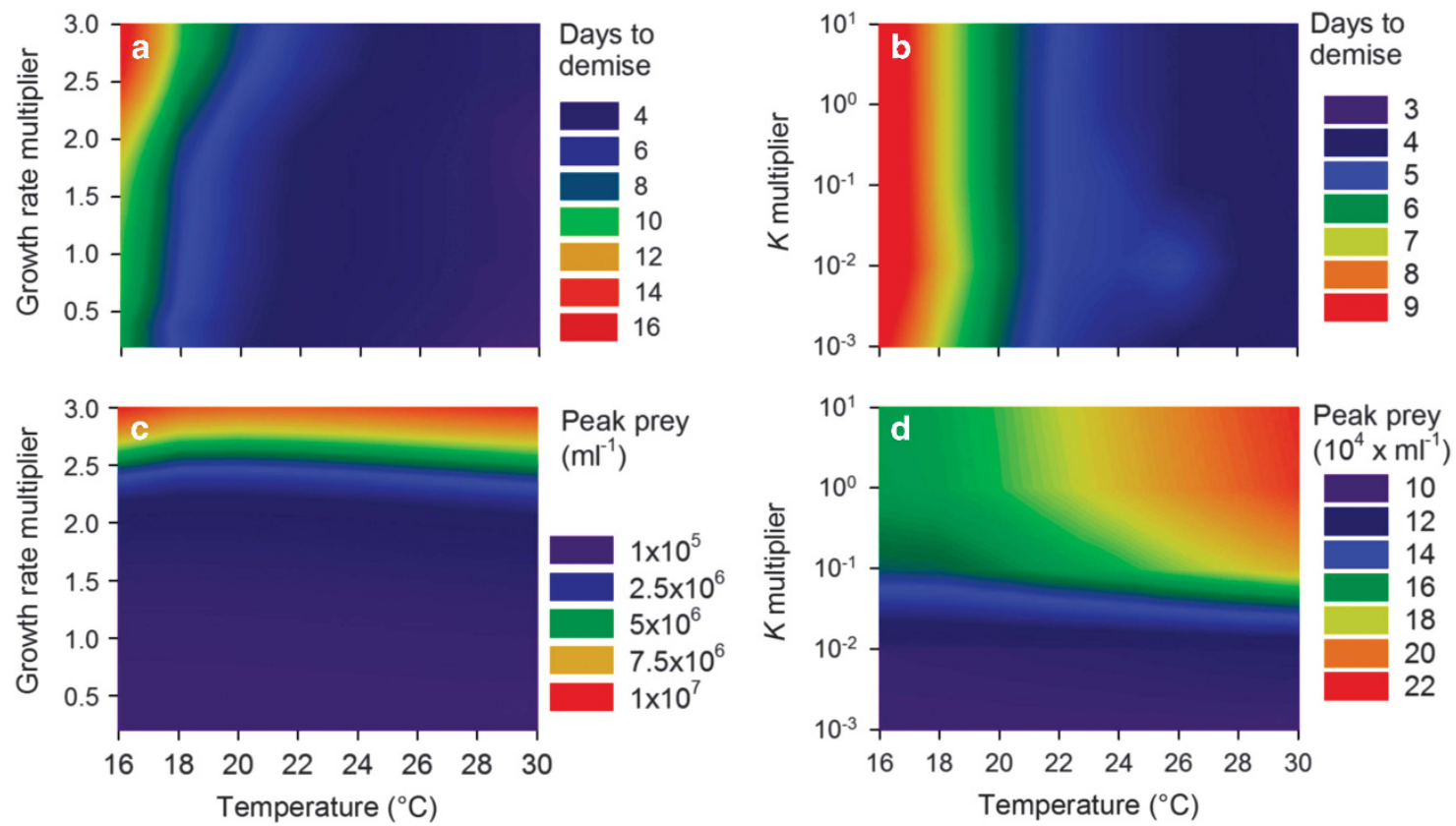

Figure 7 The effect of altering prey growth rate $\left(r_{\mathrm{p}}\right)$ and carrying capacity $(K)$ on the time required for the predator to drive the prey to near extinction (that is, $\sim 4 \times 10^{3}$ cells $\mathrm{ml}^{-1}$ ) and the peak abundance of prey.

model predictability, especially in systems where key taxa rather than communities drive dynamics (for example, algal blooms). Furthermore, although they do not conform to the expected Arrhenius relationship, it may also be important to consider linear rather than exponential functions when evaluating mechanistic temperature-dependencies, such as those impacting searching rate and handling time in the functional response (for example, Dell et al., 2014; Vasseur and McCann, 2005).

Second, and more critically, consumer grazing and growth rates of our consumer exhibit a clear interaction between temperature and prey abundance (Figure 2). Such nonlinear interactions between resource, temperature, and vital rates are likely the norm (Kimmance et al., 2006; Chen et al., 2012; Yang et al., 2013; Cross et al., 2015). Thus, rather than focusing on thermal sensitivities of maximal rates (Figure 1), as others have done (for example, Rose and Caron, 2007), we argue that it is essential for studies that address temperature impacts on population dynamics to consider temperature-prey interactions. Consequently, we have adopted the IR approach to modelling (equations 5 and 6, Fenton et al., 2010). Rather than using the well-established and typically applied Rosenzweig-MacArthur structure (or variants of it; Turchin, 2003) where consumer growth is a function of ingested prey, the IR structure independently parameterises consumer ingestion and growth (for example, Figure 2). In doing so, it allows for the effect of prey abundance on conversion efficiency and predator mortality rate (Fenton et al., 2010; Minter et al., 2011; Montagnes and Fenton, 2012; Li and Montagnes, 2015), and critically when assessing climate change scenarios, it provides a mechanism to include temperature effects on ingestion and growth parameters, independently (Kimmance et al., 2006; Yang et al., 2013). Again, we argue that when exploring the impact of temperature on producer-consumer dynamics, here and elsewhere, it is appropriate to take this approach, as functional and numerical responses exhibit distinct temperature sensitivities.

Finally, as indicated in the Introduction, mixotrophic grazers are now being recognised as the norm in aquatic systems, and modelling their responses provides new challenges. These may be accommodated within a modified Rosenzweig-MacArthur structure (Cropp and Norbury, 2015) but can equally and possibly more parsimoniously (that is, fewer parameters) be embedded in the IR model structure. Our model consumer, which is mixotrophic, both increases its photosynthetic capacities at lower prey abundances and reduces its grazing efforts (Wilken et al., 2013); similar strategies are undoubtedly common to other mixotrophs and need to be accounted for. Furthermore, mixotroph mortality does not occur when the prey are exhausted, as these consumers can sustain themselves autotrophically (Sanders, 2011). These characteristics can be embedded within the IR structure: 1) the temperatureinfluenced functional response (Figure 2a) included a low but apparent threshold level, below which prey consumption ceased; 2) the temperature-influenced numerical response (Figure 2b) included positive growth when prey were absent, and this varied with temperature; and 3) the final abundance of the consumer, after prey were exhausted, was dependent on the maximum prey abundance, as final yield was 
dependent on this proxy of the total available resource (Figure 5), that is, the consumer did not die due to starvation when prey were exhausted as is the case for strict heterotrophs, rather it maintained zero net growth at its maximum abundance through autotrophy. These modifications, representing ecophysiological phenomena associated with mixotrophy, were included in the model structure (equations 5 and 6), providing simulations that reflected observed population dynamics (Figures 3, 4 and 6, Supplementary Figures S2). However, some clear exceptions occurred. At the lowest temperatures, near the thermal tolerance of the prey where dynamics are unstable, the model was a poor predictor. Likewise, in some simulations (for example, Figure $3,19^{\circ} \mathrm{C}$ ), the maximum prey and final consumer abundances were poorly estimated. We suggest that in some cases these poor fits are related to the abundances estimates in the microcosms, used to initiate simulations; the model can be sensitive to small errors in initial abundance; for example, at $19^{\circ} \mathrm{C}$ if the initial consumer density was $1 \times 10^{3}$ rather than $2 \times 10^{3} \mathrm{ml}^{-1}$ (a conceivable measurement error at such low levels), the model provides a much better match with the microcosm data (see Figure 3, thin lines at $19^{\circ} \mathrm{C}$ ). Regardless, it is apparent that, on average (Figures 4 and 6), our revised IR framework (equations 5 and 6) provides a useful model for exploring trends, with reasonable predictive ability.

Impacts of differing thermal sensitivities to microbial consumer-prey dynamics

Once tested, the model was used to address a key aspect of global climate change on ecosystem dynamics: the impact of temperature on top-down control of bloom forming micro-autotrophs. We clearly indicate that increased temperature favours the protistan consumer and the demise of the primary producer, offering the first validation of predictions from a growing body of theory (Allen et al., 2005; Rose and Caron, 2007; O'Connor et al., 2011; Chen et al., 2012; Gilbert et al., 2014). This has implications for dynamics, across ecosystems and communities. Here we focus on protistan grazers, as they are a dominant component of many aquatic ecosystems (Kirchman, 2012), but also because protists are good ecological models, that provide strong guidance on how future work can be directed when examining less tractable systems (Montagnes et al., 2012). Critically, our model simulations agree with observed population dynamics and indicate the increased ability of the consumer to control the producer with rising temperature. This provides the first rigorous test of the prediction that greater thermal sensitivity of heterotrophs, relative to autotrophs, could reduce the impact of algal blooms, and it appears to be the first specific test of the general auto-heterotroph thermal sensitivity hypothesis.

We then explored the impact of bottom-up effects on the predator-prey dynamics. Chen et al. (2012) suggest, through meta-analysis and modelling, that trophic status of the water (that is, bottom-up nutrient control of microalgae) alters the predictions that top-down control of prey will increase with rising temperature (Rose and Caron, 2007). Chen et al. (2012) proposed that for oligotrophic waters where phytoplankton growth and biomass are reduced, temperature has an opposite effect, releasing prey from top-down control. Under a wide range of increased and reduced growth rates and carrying capacities, our analysis does not support a shift in the general response: the consumer always controls the prey, albeit over slightly different time-scales depending on the prey attributes (Figure 7). The predictions of Chen et al. (2012) may apply more appropriately at a community level where shifts in taxonomic composition affect outcomes, and as they admit the inclusion of secondary consumers may have further complicated their analysis. We also emphasise that our simulations, which were based on measurements under nutrient replete conditions, did not allow for nutrient competition between the auto- and mixotroph. Wilken et al. (2014) found that when nutrients were high and there was competition for them: Ochromonas (mixotroph) was the poorer competitor and unable to drive Microcystis (autotroph) towards extinction, but when nutrients were low, it could. Surprisingly, our simulations which were based on nutrient replete cultures of the same taxa, do not support this argument, nor do our time-series data (Figure 3,Supplementary Figures S2). Clearly, assessing the interactions of temperature and other factors that affect prey dynamics requires continued attention, at both consumer-prey and community levels. Furthermore, there is a need to assess how temperature influences higher trophic levels, potentially influencing trophic cascades (Montagnes et al., 2008; Seifert et al., 2015).

\section{Possible impacts on cyanobacteria}

Finally, we briefly relate our findings directly to cyanobacteria. Evidence indicates that temperature rise will increase the proportion of cyanobacteria in lakes, with laboratory-, field-, modelling-, and metaanalyses revealing that blooms will increase with increasing temperature (see the special issue edited by Newcombe et al., 2012; but also see O'Neil et al., 2012; Paerl and Otten, 2013). The underlying mechanisms driving blooms are complex, including change in metabolic rates, competition, prey escape behaviours, formation of surface aggregates, shifts in water column stratification, and trophic cascades. Here we have focused on an additional key aspect of this complex system: top-down control by protist grazing.

Globally, many toxic bloom forming cyanobacteria are thought to be poorly controlled by metazoan grazing (Paerl and Otten, 2013), although there are predictions that as blooms become more frequent, zooplankton may adapt to exploit this resource (Ger et al., 2014). Recently, though, it has been 
proposed that protistan grazers affect toxic cyanobacteria populations, potentially even controlling short term blooms (Wilken et al., 2010; Kobayashi et al., 2013, and references within). As indicated above, protists are major grazers in pelagic systems, with small flagellates being important consumers of cyanobacteria. More specifically Ochromonas appears to be ubiquitous in shallow lakes where cyanobacteria bloom (Van Donk et al., 2009), suggesting it could be important. However, the recent reviews that assess the fate of cyanobacteria fail to consider the role of these grazers.

Our data support predictions that mixotrophic flagellates can be important grazers of cyanobacteria, with Ochromonas potentially even being a means of biocontrol (Wilken et al., 2010; Combes et al., 2013; Kobayashi et al., 2013; Mohamed and Al-Shehri, 2013; Wilken et al., 2014). But to what extent do our findings directly apply to Microcystis blooms in the field? As with several other cyanobacteria, when its densities are high Microcystis may escape predation by forming aggregates and ultimately producing large surface masses that are inaccessible to consumers (Yang and Kong, 2012; Paerl and Otten, 2013). In our experiments, as has been the case for other experimental studies that argue for the importance of Ochromonas as a grazer (Wilken et al., 2014), Microcystis remained as single cells. Therefore, in this study, we have not accounted for aggregates as a prey refuge. However, our microcosm incubations and simulations (Supplementary Figure S3) were initiated at levels where cyanobacteria, and specifically Microcystis, can be a hazard, even in the single cell state (Paerl and Otten, 2013). We, therefore, suggest that the potential for blooms to form, rather than demise of toxic blooms composed of large aggregates, may be controlled by protistan grazing, that is, this control of blooms would never be observed, as blooms would be suppressed before they occurred! Notably, our analysis predicts that the strength of such control will increase with temperature rise (Figures 3 and 4).

Thus, although an increase in temperature may stimulate cyanobacterial blooms for a range of reasons, protistan top-down control should be enhanced by increasing temperature, counteracting, to some extent, bloom stimulating factors. It, therefore, seems an oversight that models that assess temperature effects on blooms have not included grazing by protists. For instance, simulations that assess trophic cascades, such as Daphnia removal by introduction of fish, may need to recognise the ensuing release of pressure on protists and the subsequent increase in mixotrophic predation on cyanobacteria.

\section{Conclusion}

It is clear that a revised approach to modelling and data collection is required to adequately assess the ecological impact of the disparate thermal sensitivities of auto- and mixotrophic microbes. We offer the IR approach, as an ecophysiologically based framework to do so and justify its application. We also recognise the need to continue to improve this structure, by adding such complexity as the effects of predator nutritional history (Li et al., 2013), predator interference competition (Delong and Vasseur, 2013), and ultimately a more mechanistic approach to modelling temperature on growth and grazing parameters (Dell et al., 2014; Vasseur and McCann, 2005).

More specifically, we suggest that careful assessment of the role of protists, especially mixotrophs, is required to determine potential for microalgae, including cyanobacteria, to bloom. Finally, we recognise the need to add further, essential, complexity to models that assess temperature impacts on protist-algal dynamics, including: the effect of top-down control on the protists; the potential for temperature-nutrient interactions on bottom-up control of autotrophic prey; and the potential for prey to escape predation by forming large, inedible aggregates. These provide some of the main directions for experimental ecology and commensurate modification of our revised IR model.

\section{Conflict of Interest}

The authors declare no conflict of interest.

\section{Acknowledgements}

This study was supported by the National Natural Science Foundation of China (31270504), the Natural Science Foundation of Jiangsu Province (BK2011073), and the Priority Academic Program Development of Jiangsu Higher Education Institutions. We thank several colleagues who offered constructive comments on early drafts of this paper and to anonymous reviewers who provided useful comments that improved this work.

\section{Author contributions}

ZY and DJSM developed the theory, designed and directed the study, and performed the analysis. LZ, XXZ, and JW conducted the laboratory work, with guidance and assistance from ZY and DJSM. DJSM and ZY wrote and revised the manuscript.

\section{References}

Aberle N, Bauer B, Lewandowska A, Gaedke U, Sommer U. (2012). Warming induces shifts in microzooplankton phenology and reduces time-lags between phytoplankton and protozoan production. Mar Biol 159: 2441-2453.

Allen AP, Gillooly JF, Brown JH. (2005). Linking the global carbon cycle to individual metabolism. Funct Ecol 19: 202-213.

Båmstedt U, Gifford DJ, Irigoien X, Atkinson A, Roamn M. (2000). Feeding. In: Harris RP, Wiebe PH, Lenz J, Skjoldal HR, Huntley M (eds). ICES Zooplankton 
Methodology Manual. Academic Press: San Deigo, CA, USA, pp 297-399.

Bissinger JE. (2008). Predicting microagal specific growth rate in response to temperature and light: a multispecies approach. $\mathrm{PhD}$ thesis, University of Liverpool, Liverpool, UK.

Caron DA, Worden AZ, Countway PD, Demir E, Heidelberg KB. (2009). Protists are microbes too: a perspective. ISME J 3: 4-12.

Chen B, Landry MR, Huang B, Liu H. (2012). Does warming enhance the effect of microzooplankton grazing on marine phytoplankton in the ocean? Limnol Oceanogr 57: 519-526.

Combes A, Dellinger M, Cadel-six S, Severine A, Comte K. (2013). Ciliate Nassula sp. grazing on a microcystinproducing cyanobacterium (Planktothrix agardhii): impact on cell growth and in the microcystin fractions. Aquat Toxicol 126: 435-441.

Cropp R, Norbury J. (2015). Mixotrophy: the missing link in consumer-resource-based ecologies. Theor Ecol 8: $245-260$.

Cross WF, Hood JM, Benstead JP, Huryn AD, Nelson D. (2015). Interactions between temperature and nutrients across levels of ecological organization. Global Change Biol 21: 1025-1040.

Dell AI, Pawar S, Savage VM. (2014). Temperature dependence of trophic interactions are driven by asymmetry of species responses and foraging strategy. J Anim Ecol 83: 70-84.

Delong JP, Vasseur DA. (2013). Linked exploitation and interference competition drives the variable behavior of a classic predatorprey system. Oikos 122: 1393-1400.

Downing JA. (2014). Productivity of freshwater ecosystems and climate change. In: Freedman B (ed). Global Environmental Change. Springer-Verlag: Springer, Netherlands, pp 221-229.

Fenton A, Spencer M, Montagnes DJS. (2010). Parameterising variable assimilation efficiency in predatorprey models. Oikos 119: 1000-1010.

Flynn KJ, Stoecker DK, Mitra A, Raven JA, Glibert PM, Hansen PJ et al. (2013). Misuse of the phytoplanktonzooplankton dichotomy: the need to assign organisms as mixotrophs within plankton functional types. J Plankton Res 35: 3-11.

Fussmann KE, Schwarzmüller F, Brose U, Jousset A, Rall BC. (2014). Ecological stability in response to warming. Nat Clim Change 4: 206-210.

Ger KA, Hansson LA, Lürling M. (2014). Understanding cyanobacteria-zooplankton interactions in a more eutrophic world. Freshwater Biol 59: 1783-1798.

Gilbert B, Tunney TD, McCann KS, DeLong JP, Vasseur DA, Savage V et al. (2014). A bioenergetic framework for the temperature dependence of trophic interactions. Ecol Lett 17: 902-914.

Heinbokel JF. (1978). Studies of the functional role of tintinnids in the Southern California Bight. 1. Grazing and growth rates in laboratory cultures. Mar Biol 47: 177-189.

Heinze AW, Truesdale CL, Devaul SB, Swinden J, Sanders RW. (2013). Role of temperature in growth, feeding, and vertical distribution of the mixotrophic chrysophyte Dinobryon. Aquat Microb Ecol 71: 155-163.

Hessen DO, Kaartvedt S. (2014). Top-down cascades in lakes and oceans: different perspectives but same story? J Plankton Res 36: 914-924.
Kim BR, Nakan S, Kim BH, Han MS. (2006). Grazing and growth of the heterotrophic flagellate Diphylleia rotans on the cyanobacterium Microcystis aeruginosa. Aquat Microb Ecol 45: 163-170.

Kimmance S, Atkinson D, Montagnes DJ. (2006). Do temperature-food interactions matter? Responses of production and its components in the model heterotrophic flagellate Oxyrrhis marina. Aquat Microb Ecol 42: $63-73$.

Kirchman DL. (2012). Processes in Microbial Ecology. Oxford University Press: Oxford, UK.

Knies JL, Kingsolver JG. (2010). Erroneous Arrhenius: modified arrhenius model best explains the temperature dependence of ectotherm fitness. Am Nat 176: 227-233.

Kobayashi Y, Hodoki Y, Ohbayashi K, Okuda N, Nakano SI. (2013). Grazing impact on the cyanobacterium Microcystis aeruginosa by the heterotrophic flagellate Collodictyon triciliatum in an experimental pond. Limnology 14: 43-49.

Kosten S, Huszar VLM, Bécares E, Costa LS, Van Donk E, Hansson L-A et al. (2012). Warmer climates boost cyanobacterial dominance in shallow lakes. Global Change Biol 18: 118-126.

Li J, Montagnes DJ. (2015). Restructuring fundamental predator-prey models by recognising prey-dependent conversion efficiency and mortality rates. Protist 166: 211-223.

Li J, Fenton A, Kettley L, Robert P, Montagnes DJS. (2013). Reconsidering the importance of the past in predatorprey models: both numerical and functional responses depend on delayed prey densities. Proc Royal Soc B 280: 20131389.

Minter EJA, Fenton A, Cooper J, Montagnes DJ. (2011). Prey-dependent mortality rate: a critical parameter in microbial models. Microb Ecol 62: 155-161.

Mitra A, Flynn KJ, Burkholder JM, Berge T, Calbet A, Raven JA et al. (2014). The role of mixotrophic protists in the biological carbon pump. Biogeosciences 11: 995-1005.

Mohamed ZA, Al-Shehri AM. (2013). Grazing on Microcystis aeruginosa and degradation of microcystins by the heterotrophic flagellate Diphylleia rotans. Ecotoxicol Environ Safety 96: 48-52.

Montagnes DJ, Fenton A. (2012). Prey-abundance affects zooplankton assimilation efficiency and the outcome of biogeochemical models. Ecol Model 243: 1-7.

Montagnes DJ, Kimmance SA, Atkinson D. (2003). Using Q (10): can growth rates increase linearly with temperature? Aquat Microb Ecol 32: 307-313.

Montagnes DJ, Morgan G, Bissinger JE, Atkinson D, Weisse T. (2008). Short-term temperature change may impact freshwater carbon flux: a microbial perspective. Global Change Biol 14: 2823-2838.

Montagnes DJ, Roberts E, Lukes J, Lowe CD. (2012). The rise of model protozoa. Trends Microbiol 20: 184-191.

Newcombe G, Chorus I, Falconer I, Lin TF. (2012). Cyanobacteria: Impacts of climate change on occurrence, toxicity and water quality management. Water Res 46: 1347-1348.

Nishibe Y, Kawabata Z, Nakano S. (2002). Grazing on Microcystis aeruginosa by the heterotrophic flagellate Collodictyon triciliatum in a hypertrophic pond. Aquat Microb Ecol 29: 173-179.

O'Connor MI, Gilbert B, Brown CJ. (2011). Theoretical predictions for how temperature affects the dynamics of interacting herbivores and plants. Am Nat 178: 626-638. 
O’Neil JM, Davis TW, Burford MA, Gobler CJ. (2012). The rise of harmful cyanobacteria blooms: the potential roles of eutrophication and climate change. Harmful Algae 14: 313-334.

Paerl HW. (2014). Mitigating harmful cyanobacterial blooms in a human- and climaticallyimpacted world. Life 4: 988-1012.

Paerl HW, Otten TG. (2013). Harmful cyanobacterial blooms: Causes, consequences, and controls. Microb Ecol 65: 995-1010.

Reynolds CS. (1984). The Ecology of Freshwater Phytoplankton. Cambridge University Press: Cambridge.

Rippka R, Deruelles J, Waterbury JB, Herdman M, Stanier RY. (1979). Generic assignments, strain histories and properties of pure cultures of cyanobacteria. J Gen Microbiol 111: 1-61.

Rose JM, Caron DA. (2007). Does low temperature constrain the growth rates of heterotrophic protists? Evidence and implications for algal blooms in cold waters. Limnol Oceanogr 52: 886-895.

Sanders RW. (2011). Alternative nutritional strategies in protists: symposium introduction and a review of freshwater protists that combine photosynthesis and heterotrophy. J Eukaryot Microbiol 58: 181-184.

Seifert LI, Weithoff G, Gaedke U, Vos M. (2015). Warminginduced changes in predation, extinction and invasion in an ectotherm food web. Oecologia 178: 485-496.

Turchin P. (2003). Complex Population Dynamics: A Theoretical/empirical Synthesis. Princeton University Press: Princeton, NJ.

Van Donk E, Cerbin S, Wilken S, Helmsing NR, Ptacnik R, Verschoor AM. (2009). The effect of a mixotrophic chrysophyte on toxic and colony-forming cyanobacteria. Freshwater Biol 54: 1843-1855.

Van Wichelen J, van Gremberghe I, Vanormelingen P, Vyverman W. (2012). The importance of morphological versus chemical defences for the bloom-forming cyanobacterium Microcystis against amoebae grazing. Aquat Ecol 46: 73-84.

Vasseur DA, McCann KS. (2005). A mechanistic approach for modeling temperature-dependent consumerresource dynamics. Am Nat 166: 184-198.

Wilken S, Huisman J, Naus-Wiezer S, Van Donk E. (2013). Mixotrophic organisms become more heterotrophic with rising temperature. Ecol Lett 16: 225-233.

Wilken S, Verspagen JM, Naus-Wiezer S, Van Donk E, Huisman J. (2014). Biological control of toxic cyanobacteria by mixotrophic predators: an experimental test of intraguild predation theory. Ecol Appl 24: 1235-1249.

Wilken S, Wiezer SMH, Huisman J, Van Donk E. (2010). Microcystins do not provide anti-herbivore defence against mixotrophic flagellates. Aquat Microb Ecol 59: 207-216.

Yang Z, Kong FX. (2012). Formation of large colonies: a defense mechanism of Microcystis aeruginosa under continuous grazing pressure by flagellate Ochromonas sp. J Limnol 71: 61-66.

Yang Z, Lowe CD, Crowther W, Fenton A, Watts PC, Montagnes DJS. (2013). Strain-specific functional and numerical responses are required to evaluate impacts on predator-prey dynamics. ISME J 7: 405-416.

(c) (1) (2) This work is licensed under a Creative Commons Attribution-NonCommercialShareAlike 4.0 International License. The images or other third party material in this article are included in the article's Creative Commons license, unless indicated otherwise in the credit line; if the material is not included under the Creative Commons license, users will need to obtain permission from the license holder to reproduce the material. To view a copy of this license, visit http://creativecommons.org/ licenses/by-nc-sa/4.0/

Supplementary Information accompanies this paper on The ISME Journal website (http://www.nature.com/ismej) 